14.2

\title{
Пористый кремний как наноматериал для дисперсных транспортных систем направленной лекарственной доставки ко внутреннему уху
}

\author{
(C) Ю.М. Спивак, ${ }^{1}$ А.О. Белорус,, А.А Паневин, ${ }^{2}$ С.Г. Журавский, ${ }^{2,3}$ В.А. Мошников, ${ }^{1}$ К. Беспалова, ${ }^{1}$ \\ П.А. Сомов, ${ }^{1}$ Ю.М. Жуков, ${ }^{4}$ А.С. Комолов, ${ }^{4}$ Л.В. Чистякова, ${ }^{4}$ Н.Ю. Григорьева ${ }^{4}$ \\ ${ }^{1}$ Санкт-Петербургский государственный электротехнический университет „ЛЭТИ“ им. В.И. Ульянова (Ленина), \\ 197376 Санкт-Петербург, Россия \\ ${ }^{2}$ Первый Санкт-Петербургский государственный медицинский университет им. акад. И.П. Павлова, \\ 197022 Санкт-Петербург, Россия \\ ${ }^{3}$ Национальный медицинский исследовательский центр им. В.А. Алмазова, \\ 197341 Санкт-Петербург, Россия \\ ${ }^{4}$ Санкт-Петербургский государственный университет, \\ 199034 Санкт-Петербург, Россия \\ e-mail: ymkanageeva@yandex.ru
}

(Поступило в Редакцию 9 февраля 2018 г.)

Методом электрохимического анодного травления монокристаллического кремния в электролите на основе раствора HF с последующим изменением режимов ультразвуковой обработки и гомогенизации получены образцы частиц пористого кремния (por-Si) в трех диапазонах размеров: 60-80, 250-300, 500-600 nm. Проведена комплексная характеризация частиц методами растровой электронной микроскопии, фотонной кросс-корреляционной и рентгеновской фотоэлектронной спектроскопий. На моделях биологической совместимости in vitro на одноклеточных организмах инфузорий Paramecium caudatum Keln показана низкая токсичность образцов в концентрациях, применяемых при внутривенном введении. Системное биораспределение in vivo изучали для образца por-Si размером 60-80 nm на взрослых крысах стока Wistar. Вводимые нанообъекты обнаружены в тканях печени и сердца без существенных изменений формы, размеров и преимущественно в окисленном состоянии. Возможности применения образцов por-Si в качестве матриц для транспортировки лекарственных препаратов при внутривенном введении изучены по оценке интенсивности ототропного эффекта гентамицина. Объективным аудиологическим методом исследования амплитуды отоакустической эмиссии обнаружен наибольший отодепрессивный эффект гентамицина при использовании в качестве дисперсной системы лекарственной доставки частиц por-Si субмикронного размера $(500-600 \mathrm{~nm})$. Таким образом, показано, что модификации условий синтеза наночастиц por-Si являются перспективными направлениями получения физико-химических параметров транспортных частиц, оптимальных для конкретных задач направленной лекарственной доставки.

DOI: $10.21883 / J T F .2018 .09 .46427 .57-18$

\section{1. Введение}

Стратегия направленной (адресной, таргетной) лекарственной доставки является современным направлением повышения эффективности фармакотерапии [1-4]. Центральным вопросом этой технологии является разработка дисперсных транспортных систем (ДТС) для целевого биораспределения парентерально (внутривенно) вводимых лекарственных веществ (ЛВ).

Известным материалом для конструирования контейнеров-носителей оказываются кремнийсодержащие соединения, в частности пористый кремний (por-Si). Технологическими преимуществами этого соединения для биомедицинских задач оказываются технологичность, возможность создания дисперсных конструкций в широком диапазоне параметров (размеров, морфологии поверхности, пористости, диаметра пор, удельной площади поверхности, физико-химического состава), многофункционального использования (как матрицы-носителя, в качестве маркера, сенсора, катализатора) а также биосовместимость (низкая токсичность) и биодеградируемость [1,5-11].

Подчеркнем, что свойства, приобретаемые выбором исходного материала и технологических условий получения, выделяют пористый кремний в особый класс наноматериалов с возможностью произвольной регуляции оптических, электрофизических, каталитических, химических параметров [1,12-18]. Так, выбором типа и уровня легирования монокристаллического кремния достигается возможность получать поверхность с различным химическим составом и электронными свойствами $[12,13]$. В зависимости от технологических условий получения можно варьировать параметры пористой текстуры в широком диапазоне геометрических характеристик (тип текстуры, удельная площадь поверхности, распределение пор по размерам, пористость) $[1,5,15]$. От особенностей технологии получения также будет зависеть и состав адсорбционных центров на поверхности пористого кремния [17]. Все эти возможности необходимо учитывать при получении композиционных материалов на основе por-Si, поскольку характер адсорб- 
ции второй фазы в нем связан не только с природой фазы и методом ее введения, но и со свойствами поверхности и текстуры пористого кремния [7,19].

При разработке ДТС на основе частиц por-Si вышеперечисленные особенности крайне важны [1]. Морфология и состав поверхности por-Si будут существенно определять возможность и характер закрепления молекул ЛВ в носителе. От пористости и размера частицы зависит ее „грузовая емкость“. От характеристик текстуры пористого кремния (микро-, мезо-, макро- или смешанный тип) будут зависеть эффекты старения материала $[15,16]$, которые напрямую определяют интенсивность процессов биодеградации in vivo. Произвольно изменяя удельную площадь поверхности пористых частиц, возможно контролировать скорость высвобождения ЛВ в организме (достигать пролонгированного действия или наоборот сокращать его). Кроме того, такие параметры наночастиц как размеры, форма, морфология и состав поверхности, заряд могут существенно влиять на биораспределение частиц, их биосовместимость или токсичность. Таким образом, для конкретных вопросов направленной лекарственной доставки (НЛД) экспериментальная разработка ДТС на основе частиц пористого кремния может достигаться произвольным выбором типа пористого кремния и условий его получения.

Одной из актуальных клинических задач для НЛД является технология лекарственного доступа в органы, функционирующие в условиях гистогематических барьеров, в частности, ко внутреннему уху. Гематолабиринтный барьер (ГЛБ), формируемый эндотелием капилляров сосудистой полоски, эволюционно выполняет функцию поддержания уникального микрогомеостаза жидкостных сред улитки, функционируя как высокоселективный физический и биохимический барьер [20]. Эти же его свойства не позволяют ксенобиотикам (лекарственным веществам) проницать во внутрикохлеарные структуры и оказывать ототропные эффекты. Пассивное прохождение высокомолекулярных, водорастворимых и заряженных молекул при таких условиях крайне низко [21]. Однако есть наблюдения о транспорте через ГЛБ дисперсных частиц. Так, есть наблюдения, что заряженные квантовые точки имеют более высокую эффективность интракохлеарной интернализации, чем нейтральные точки, а анионные квантовые точки имеют наибольшую скорость проникновения [22]. Кроме того, показано, что наночастицы сферической формы имеют наибольшую способность проникновения через ГЛБ по сравнению со стержнеобразными частицами [23]. Предпочтительный размер частиц для получения целевого интракохлеарного доступа остается дискуссионным. При этом очевидно, что он будет зависеть от способа инкорпорации ДТС (внутривенное введение, местное интратимпанальное, транстубарное, эндоауральное). Помимо размера, другими важными нанофармакологическими характеристиками наночастиц-носителей рассматриваются: форма, морфология, химический состав, зарядовое состояние поверхности $[21,23]$, оптимальные параметры которых для осуществления доступа ко внутреннему уху также остаются открытыми.

Цель настоящей работы - разработать транспортные контейнеры для ДТС, обеспечивающие НЛД к структурам внутреннего уха при внутривенном введении лекарственных препаратов.

Для достижения поставленной цели было поставлено четыре задачи:

а) разработать технологию синтеза, получить и охарактеризовать частицы пористого кремния трех размеров $(60-80,250-300,500-600 \mathrm{~nm})$;

б) оценить биосовместимость полученных образцов наночастиц пористого кремния на тестовых моделях одноклеточных организмов in vitro;

в) оценить in vivo возможности системного биораспределения образца наночастиц пористого кремния размером 60-80 nm на примере тканей печени и миокарда;

г) провести сравнение полученных образцов наночастиц по эффективности образованных на их основе ДТС, развивающих наибольший ототропный эффект переносимого фармакологического препарата.

\section{2. Экспериментальные методы и материалы}

\section{1. Технологическая часть}

\subsection{1. Методика получения частиц пористого кремния}

Частицы пористого кремния (por-Si) получали в два этапа. На первом этапе формировались слои пористого кремния методом электрохимического анодного травления монокристаллического кремния марки КЭФ-4,5 (111) в электролите на основе водно-спиртового раствора HF [24]. Технологические условия синтеза подбирались таким образом, чтобы получить поверхность с гидрофильными свойствами [17,25]. Этим создавались наилучшие условия для закрепления водорастворимых молекул лекарственных соединений через гидроксильные группы, в частности, для выбранного для настоящего эксперимента гентамицина сульфата. На втором этапе для получения образца серии I слои por-Si обрабатывали ультразвуком (УЗ ванна „Сапфир“). Для получения образцов серии II и III дополнительно проводили обработку ультразвуковым гомогенизатором мощностью $600 \mathrm{~W}$ в течение $15 \mathrm{~min}$ для уменьшения размеров частиц $[10,26]$. Условия получения и последующей обработки por-Si приведены в табл. 1.

Поскольку при обработке ультразвуком получаются полидисперсные частицы por-Si, то для получения образцов в более узком диапазоне размеров проводилось разделение частиц путем центрифугирования с последующим отбором супернатанта из верхней трети пробирки. Условия центрифугирования для всех типов образцов были одинаковы: экспозиция в течение $30 \mathrm{~min}$ при $13500 \mathrm{rpm}$. 
Таблица 1. Технологические условия синтеза и получаемые параметры частиц пористого кремния

\begin{tabular}{|c|c|c|c|c|c|c|c|c|}
\hline \multirow{3}{*}{$\begin{array}{c}\text { № } \\
\text { серии }\end{array}$} & \multicolumn{6}{|c|}{ Условия получения } & \multirow{2}{*}{\multicolumn{2}{|c|}{$\begin{array}{c}\text { Диаметр частиц, } \\
\text { nm }\end{array}$}} \\
\hline & \multicolumn{3}{|c|}{ I этап } & \multicolumn{3}{|c|}{ II этап } & & \\
\hline & $\begin{array}{c}\text { Марка } \\
\text { кремния }\end{array}$ & $\begin{array}{c}J_{A} \\
\mathrm{~mA} / \mathrm{cm}^{2}\end{array}$ & $\begin{array}{c}t_{A} \\
\min \end{array}$ & $\begin{array}{c}\text { Обработка } \\
\text { У3 }\end{array}$ & $\begin{array}{l}t_{\mathrm{US}} \\
\mathrm{min}\end{array}$ & $\begin{array}{c}\text { Обработка } \\
\text { гомогенизатором }\end{array}$ & Значение & $\begin{array}{c}\text { Метод } \\
\text { определения }\end{array}$ \\
\hline I & \multirow{3}{*}{$\begin{array}{c}\text { КЭФ-4,5 } \\
(111)\end{array}$} & \multirow[b]{2}{*}{80} & \multirow{3}{*}{20} & \multirow{3}{*}{ Да } & \multirow{3}{*}{20} & Нет & $\approx 500-600$ & \multirow{2}{*}{ РЭМ } \\
\hline II & & & & & & & $\approx 250-300$ & \\
\hline III & & 15 & & & & да & $\approx 80 \pm 13$ & PCCS \\
\hline
\end{tabular}

\subsection{2. Методика функционализации частиц por-Si лекарственным препаратом (гентамицин сульфатом)}

Функционализацию поверхности частицы por-Si проводили на примере лекарственного препарата гентамицина. Это вещество в качестве „груза“ было выбрано на том основании, что обладает известным эффектом воздействия на слуховой анализатор (отодепрессивным). Располагая методической возможностью проводить объективное исследование функциональной активности слухового рецептора, нами предложено рассматривать гентамицин в качестве маркера, более или менее успешного проникновения дисперсной транспортной системы в интракохлеарные структуры.

Осаждение гентамицина на поверхности частиц проводили методом импрегнации. К $1.5 \mathrm{ml}$ дисперсии частиц пористого кремния в физиологическом растворе добавляли $0.5 \mathrm{ml}$ раствора гентамицина сульфата $(40 \mathrm{mg} / \mathrm{ml})$ (официальный препарат для внутривенного введения). Затем проба подвергалась обработке ультразвуком в течение $15 \mathrm{~min}$.

\section{2. Физические методы исследования материалов}

\subsection{1. Растровая электронная микроскопия}

Растровая электронная микроскопия (РЭМ) применялась для контроля морфологии и размеров частиц пористого кремния на этапе получения и для оценки системного биораспределения внутривенно вводимых образцов полученных частиц. Исследования проводились на приборе MiraTescanII при детекции вторичных и отраженных электронов; значения ускоряющего напряжения составляли $5-20 \mathrm{kV}$. Типичные значения увеличения составляли $10000 \times-200000 \times$.

Методика подготовки для микроскопии частиц por-Si заключалась в следующем: дисперсии por-Si центрифугировались в пробирках типа Эппендорф в течение $30 \mathrm{~min}$ при $13500 \mathrm{rpm}$ для осаждения наиболее крупных частиц (до $\approx 1-2 \mathrm{~mm})$. Проба отбиралась дозатором из верхней (прозрачной) трети пробирки, а затем каплей наносилась на подложку монокристаллического кремния марки КЭФ-0.3 (111), затем высушивалась в чашке Петри.

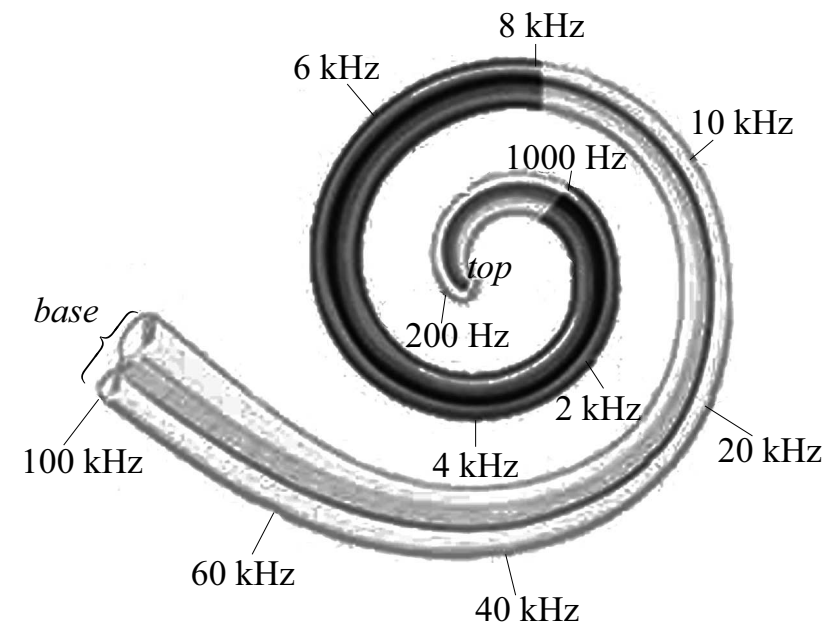

Рис. 1. Участок спирального органа, анализируемый методом ОАЭ ЧПИ в диапазоне от 1 до $8 \mathrm{kHz}$ (схема).

Анализ биораспределения частиц por-Si после внутривенной инкорпорации взрослым крысам стока Wistar, самцам (220-250g) проводили на фрагментах тканей печени и миокарда, полученных после некропсии на 3 суток после внутривенного введения суспензии наночастиц por-Si $60-80 \mathrm{~nm}$. Образцы тканей подвергались лиофильной сушке. РЭМ исследование проводилось на сколах сухих фрагментов органов в условиях предварительного нанесения на поверхность тонкого слоя углерода.

Выбор тканей печени и миокарда обусловлен следующим. Так как размеры внутреннего уха крысы малы - менее $2 \mathrm{~mm}$, а слой клеток-целей для лекарственной доставки очень тонок, то подготовка образцов для непосредственного (прямого) наблюдения и контроля доставки пористых частиц-носителей представляет собой крайне сложную задачу, требующую специализированного оборудования и отдельных методических разработок. С другой стороны, контроль биораспределения (биодоступности тканей) необходим при выборе оптимальных параметров пористых частиц на этапе отработки технологии их получения. 


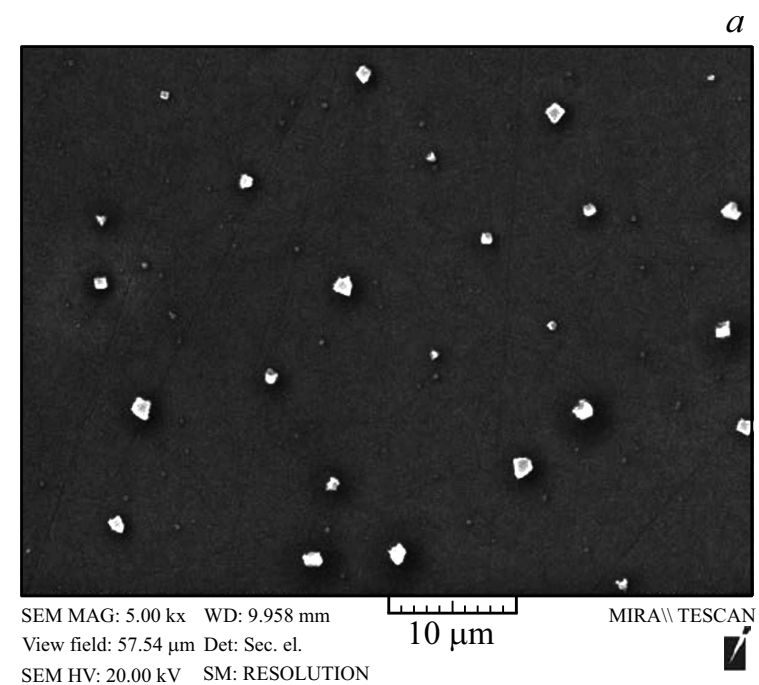

$a$
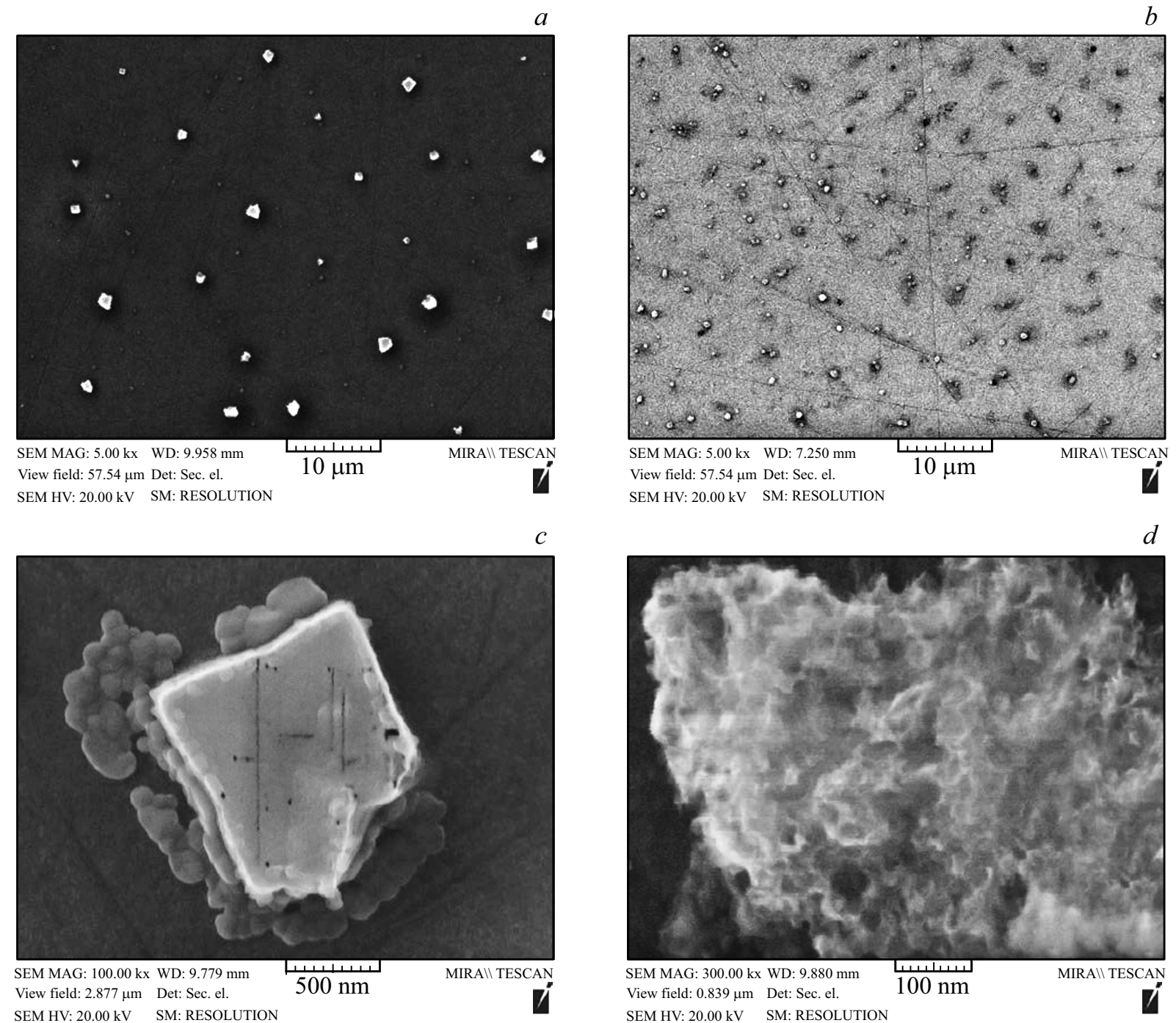

$c$
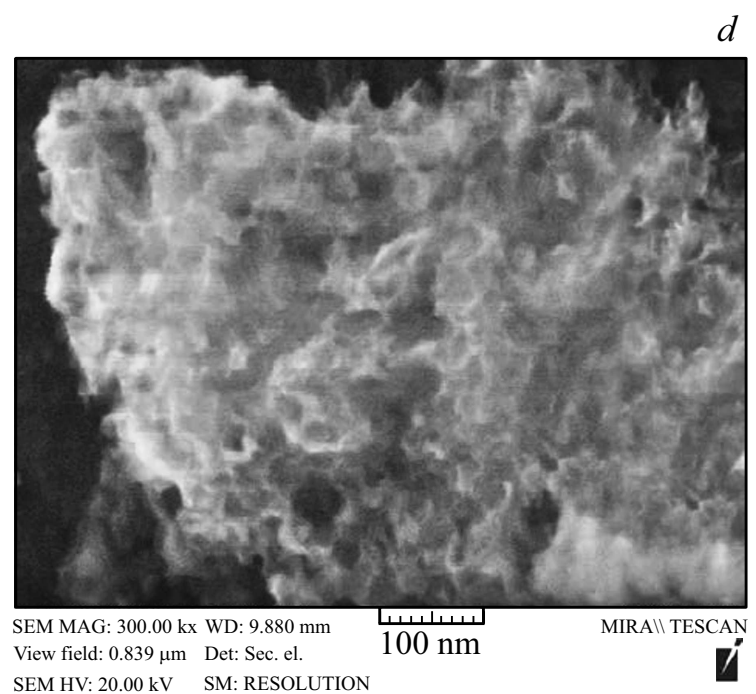

Рис. 2. Частицы пористого кремния. Обзорный вид частиц por-Si I и II серий соответственно $(a, b)$. Морфология поверхности $(c)$, мезо- и макропористая текстура поверхности $(d)$ отдельной частицы por-Si серии I.

\subsection{2. Метод спектроскопии кросс-корреляции фотонов}

Данные о размерах наименышей по гидродинамическому диаметру фракции наночастиц por-Si были получены с помощью метода спектроскопии кросс-корреляции фотонов (PCCS). Измерения проводились на спектрометре Nanophox (фирмы SYMPATEC GmbH, Германия) [27]. Предварительные исследования показали, что дисперсии por-Si в воде взаимодействуют с материалом кювет, сделанных из полистирола. Поэтому далее в работе в качестве емкостей для измерений были использованы кварцевые кюветы.

\subsection{3. Метод рентгеновской фотоэлектронной спектроскопии}

Метод рентгеновской фотоэлектронной спектроскопии (XPS) применяли для верификации наличия частиц por-Si в тканях после интернализации. Был использован комплексный фотоэлектронный спектрометр Escalab
250Xi (Thermo Fisher Scientific Inc.). Исследования проводились в условиях сверхвысокого вакуума порядка $10^{-7}$ Ра при комнатной температуре, в случае использования системы компенсации зарядки образца парциальное давление аргона в аналитической камере составляло $10^{-5} \mathrm{~Pa}$. Энергия возбуждающих фотонов составляла $1486 \mathrm{eV}$, спектры остовных уровней были измерены при энергии пропускания анализатора $20 \mathrm{eV}$. Поверхности, приготовленные ex situ, адсорбируют из воздуха кислород- и углеродсодержащие примеси [28-30], поэтому непосредственно перед XPS-измерениями проводили очистку исследованных поверхностей методом ионной бомбардировки.

\section{3. Биологическая часть}

\subsection{1. Оценка биосовместимости частиц por-Si in vitro}

Биосовместимость образцов определяли на модели in vitro по смертности инфузорий Paramecium caudatum 
Таблица 2. Результаты изучения воздействия дисперсий por-Si на биотест-объекты

\begin{tabular}{|c|c|c|c|c|c|c|}
\hline \multirow{2}{*}{ № } & \multirow{2}{*}{ Образец } & \multirow{2}{*}{$\begin{array}{c}\text { Концентрация } \\
\text { por-Si } \\
\text { (оценка) }\end{array}$} & \multicolumn{4}{|c|}{ Сроки тестирования } \\
\hline & & & $5 \mathrm{~min}$ & $1 \mathrm{~h}$ & $2.5 \mathrm{~h}$ & $24 \mathrm{~h}$ \\
\hline 1 & Вода „Бон Аква“ & 0 & 15 & 12 & 10 & 10 \\
\hline 2 & \multirow{2}{*}{$\begin{array}{c}\text { I серия } \\
\text { (группа размеров „,500-600 nm“) }\end{array}$} & $\mathrm{K}^{*}$ & 12 & 8 & 5 & 2 \\
\hline 3 & & $\mathrm{P}^{* *}$ & 16 & 16 & 16 & 14 \\
\hline 4 & \multirow{2}{*}{$\begin{array}{c}\text { II серия } \\
\text { (группа размеров „,250-300 nm“) }\end{array}$} & K & 11 & 10 & 7 & 0 \\
\hline 5 & & $\mathrm{P}$ & 10 & 9 & 9 & 4 \\
\hline 6 & \multirow{2}{*}{$\begin{array}{c}\text { III серия } \\
(\text { группа размеров „60-80 nm““) }\end{array}$} & K & 18 & 14 & 14 & 8 \\
\hline 7 & & $P$ & 16 & 16 & 12 & 10 \\
\hline
\end{tabular}

Примечание. * концентрированная дисперсия (темно-оранжевый цвет), концентрация $\approx 100 \mathrm{mg} / \mathrm{ml}$; ** разбавленная дисперсия (прозрачная), концентрация $\approx 4 \mathrm{mg} / \mathrm{ml}$.

Keln за определенный период культивации по протоколу [31]. В каждую лунку вносили $100 \mu 1$ тестируемой дисперсии, $2 \mathrm{ml}$ бутилированной питьевой воды без газа „Бон Аква“ и добавляли $10 \mu \mathrm{l}$ среды с инфузориями Paramecium caudatum Keln. Критерием токсичности пробы служит гибель более 50\% инфузорий за $24 \mathrm{~h}$.

2.3.2. Оценка ототропного эффекта гентамицина, вводимого внутривенно, с помощью дисперсных транспортных систем на основе экспериментальных образцов частиц por-Si

Возможность развития целевого биораспределения лекарственного препарата с участием образцов por-Si в качестве ДТС оценивали по интенсивности ототропного эффекта гентамицина, совместно вводимого после простого смешивания. Эксперимент проведен на 30 крысах (самцах ( стока Wistar с массой 220-250 g. Дисперсии частиц пористого кремния серий I-III в физиологическом растворе смешивались с раствором гентамицина $(40 \mathrm{mg} / \mathrm{ml})$ с получением общего объема $1 \mathrm{ml}$ и вводились внутривенно в дозе $2 \mathrm{mg} / \mathrm{ml}$ по пористому кремнию ежедневно 3 раза.

Функциональное состояние слухового анализатора оценивали по показателям амплитуды отоакустической эмиссии на частоте продукта искажения (ОАЭ ЧПИ) в диапазоне 4-6.4 kHz на приборе „Нейро-Аудио“ (ООО „Нейрософт“, Россия). Схематическое изображение зон акустической рецепции улитки крыс и тонотопического участка спирального органа, анализируемого методом ОАЭ ЧПИ, представлено на рис. 1.

Введению суспензии пористого кремния с аминогликозидным антибиотиком предшествовало однократное проведение акустической стимуляции (АC) подачей тона $1000 \mathrm{~Hz}$ интенсивностью $105 \mathrm{~dB}$ в течение 2 h. Данный способ физического кондиционирующего воздействия использован в эксперименте, исходя из литературных данных о том, что шумо- вое воздействие способствует увеличению проницаемости компонентов ГЛБ и при этом оказывается наиболее щадящим из известных [20,23,32]. Предварительное исследование показывало, что изолированное проведение такой АC не приводит к снижению амплитуды ОАЭ на изучаемом диапазоне акустической рецепции.

Амплитуда ПИ ОАЭ анализировалась за 1 сутки перед экспериментом, через $1 \mathrm{~h}$ после АС и введения суспензии, на 1, 3 и 7 суток эксперимента.

При рандомизации выделено пять групп животных (по 6 крыс в каждой):

1 группа (контрольная): АC + введение $1 \mathrm{ml}$ физиологического раствора в течение 3 days;

2 группа (контрольная): АC + введение $1 \mathrm{ml}$ раствора гентамицина $(40 \mathrm{mg} / \mathrm{kg})$ в течение 3 days;

3 группа: $\mathrm{AC}+$ введение $0.75 \mathrm{ml}$ суспензии $\mathrm{HЧ}$ por-Si $60-80 \mathrm{~nm}$ совместно с $0.25 \mathrm{ml}(10 \mathrm{mg})$ раствора гентамицина $(40 \mathrm{mg} / \mathrm{ml})$ в течение 3 days;

4 группа: $\mathrm{AC}+$ введение $0.75 \mathrm{ml}$ суспензии $\mathrm{HЧ}$ por-Si $250-300 \mathrm{~nm}$ совместно с $0.25 \mathrm{ml}(10 \mathrm{mg})$ раствора гентамицина $(40 \mathrm{mg} / \mathrm{ml})$ в течение 3 days;

5 группа: $\mathrm{AC}+$ введение $0.75 \mathrm{ml}$ суспензии НЧ por-Si $500-600 \mathrm{~nm}$ совместно с $0.25 \mathrm{ml}(10 \mathrm{mg})$ раствора гентамицина $(40 \mathrm{mg} / \mathrm{ml})$ в течение 3 days.

Стерилизацию дисперсных растворов проводили путем кипячения в течение $30 \mathrm{~min}$.

Статистическую обработку полученных результатов проводили с использованием программного пакета „SAS 9.4“. Значимость различий измеряемого параметра между группами непарных выборок для каждой временной точки оценивали с помощью непараметрического критерия Краскела-Уоллиса и критерия множественного сравнения Тьюки. Различия считали достоверными при $p<0.05$. 
$a$
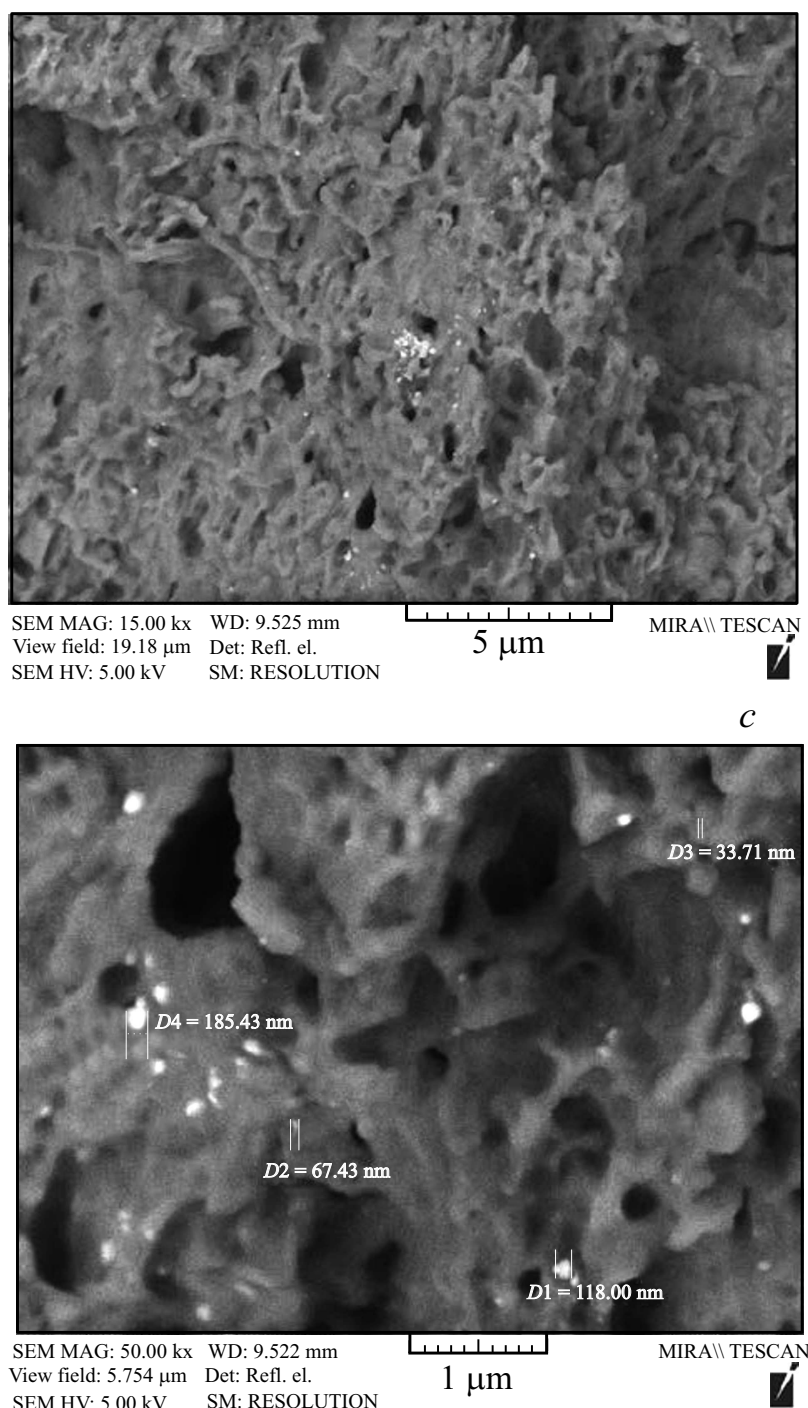

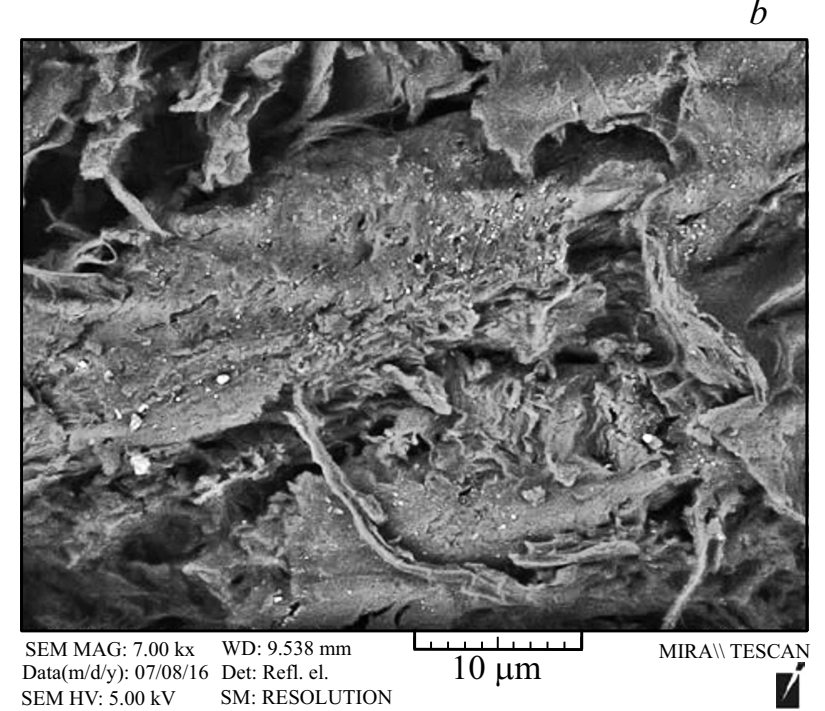

$d$

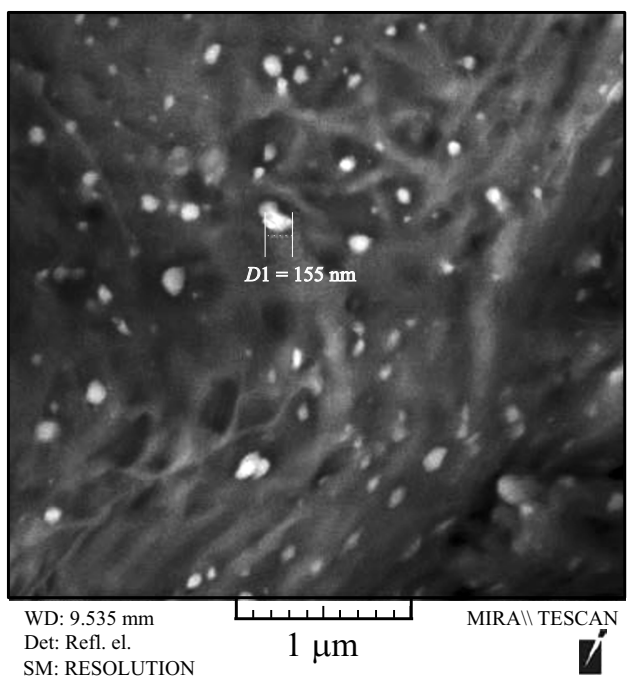

Рис. 3. Ткань печени $(a, b)$ и сердца (миокард) $(c, d)$ крысы. РЭМ изображение. Диффузное распределение электронно-плотных очагов с размерами, соответствующими размерам частиц вводимых дисперсий por-Si серии III $(80-160 \mathrm{~nm})$.

\section{3. Результаты и обсуждение}

\section{1. Характеризация частиц por-Si до введения}

По данным РЭМ (рис. 2) частицы por-Si имеют сложную полигональную форму, близкую к кубической, с округлыми (закругленными, неострыми) краями. Обработка гомогенизатором дисперсий частиц por-Si, полученных при выбранных условиях, приводит к уменьшению их размеров примерно в 2 раза (500-600 и 250-300 nm для серий I и II соответственно) (рис. 2, $a, b$ ). Полученные частицы имеют мезо- и макропористый характер поверхности (рис. 2, $c, d$ ).

Такой тип текстуры пористого кремния является, на наш взгляд, эффективным, так как, с одной стороны, за счет макропор обеспечивается доступность пористой матрицы не только на поверхности, но и в глубине пористого материала, а также ожидается снижение влияния капиллярных эффектов при адсорбции-десорбции лекарственных веществ. С другой стороны, за счет доли мезопор обеспечивается высокая развитость поверхности и пористость, что в целом будет влиять на величину полезного объема частицы для транспорта ЛВ (грузовая емкость) $[1,10,12]$.

Обсуждая морфологию частиц por-Si, отметим, что для доставки во внутреннее ухо, как упоминалось во введении, наиболее оптимальными по литературным данным являются частицы формы, близкой к сферической $[20,23]$. Так, на примере применения наночастиц повидона (поливинилпирролидона) размером 100-500 nm и формой, близкой к кубической, продемонстрирована успешная доставка (ототропность) гидрокортизона при внутривенном введении крысам [32]. При сравнении результатов, представленных на рис. 2, с полученными ранее, необходимо отметить, что наиболее желательным 
является выбор в качестве исходного материала кремния марки КЭФ-4,5 (111) при прочих равных технологических условиях. Это связано с тем, что при использовании кремния других марок формируются частицы por-Si в форме неправильных многоугольников с острыми краями, или частицы вытянутой формы, как, например, при получении por-Si из кремния марки КЭФ-0,3 (111) и КЭФ-1 (111) соответственно, что может негативно повлиять на ототропность частиц por-Si как транспортных систем лекарственной доставки $[10,26]$.

Распределение частиц por-Si по размерам для серии III определено методом PCCS, результаты приведены в табл. 1.

Оценка биологической совместимости дисперсий частиц por-Si показала, что полученные частицы por-Si в зависимости от концентрации могут проявлять различный уровень токсичности в отношении инфузорий Paramecium caudatum Keln (табл. 2). Так, при высоких значениях концентраций все серии проявляли заметную токсичность уже через $2.5 \mathrm{~h}$, при этом серия III в наименьшей степени. При разбавлении дисперсий до концентраций $\approx 4 \mathrm{mg} / \mathrm{ml}$ (показатель близкий для доз, изучаемых далее при введении in vivo) их токсичность существенно снижалась, также наименьшую токсичность показала дисперсия серии III. Наибольшую токсичность как в концентрированном, так и в разбавленном виде проявляла дисперсия серии II.

\section{2. Результаты верификации системного биораспределения дисперсной транспортной системы, образованной частицами por-Si $60-80 \mathrm{~nm}$, после внутривенного введения (на примере тканей печени и миокарда)}

Исследование фрагментов тканей печени и сердца крыс методом РЭМ после внутривенного введения частиц por-Si серии III обнаружило наличие электронноплотных частиц с формой, близкой к сферической (рис. 3). Распределение частиц в тканях наблюдалось диффузным, с тенденцией к формированию фокусов вблизи зияющих отверстий, возможно, являющихся просветами сосудов мышечного типа (мелких артерий и артериол), очевидно, сохраняющих свою форму после лиофилизации (рис. 3, $a, b$ ). Диаметр обнаруженных частиц находился в диапазоне диаметров вводимых частиц серии III: 60-80 nm - основная часть частиц, с отдельными частицами более крупного (до $185 \mathrm{~nm}$ ) и более мелкого размеров $(\approx 30-40 \mathrm{~nm})$ (рис. $3, c, d)$.

Подтверждение тканевого биораспределения вводимых частиц por-Si проводилось определением химического состава изучаемых тканей методом рентгеновской фотоэлектронной спектроскопии (XPS). C учетом табличных значений чувствительности регистрации XPS-сигнала $[30,33]$, при регистрации максимумов $\mathrm{C}_{1 s}$ и $\mathrm{O}_{1 s}$ было установлено, что преобладающими атомными компонентами являлись углерод с относительной
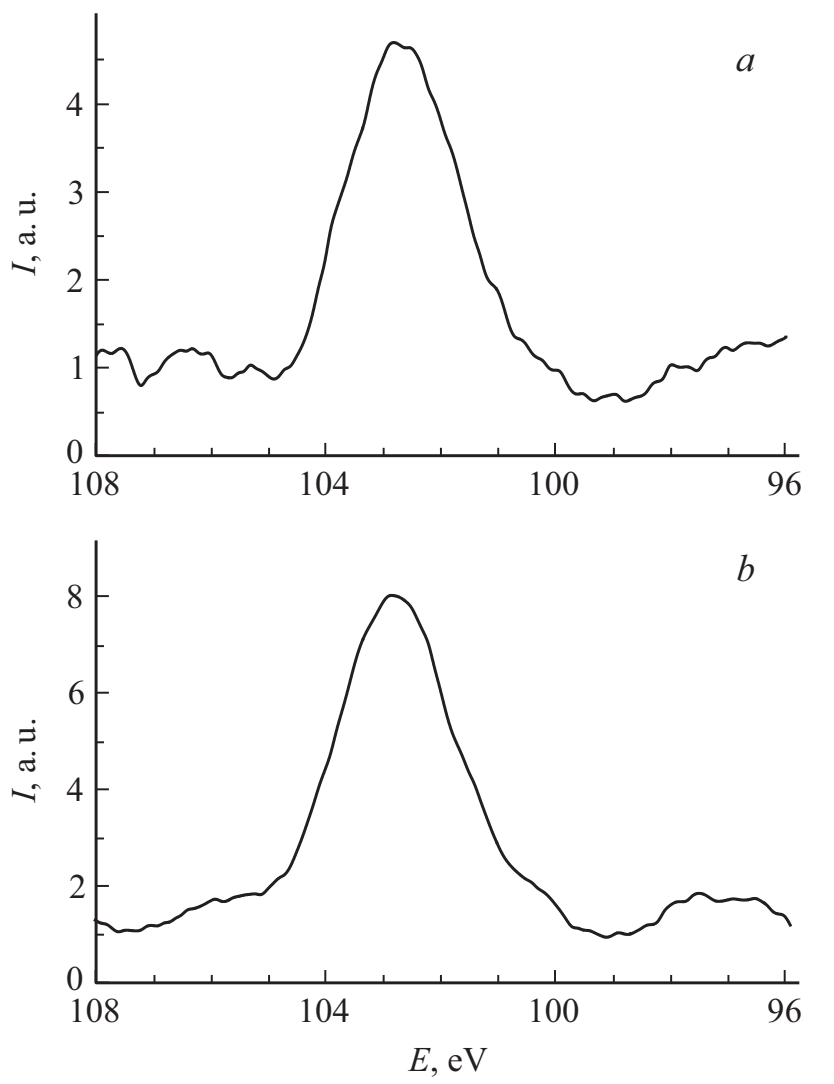

Рис. 4. Участки рентгеновского фотоэлектронного (XPS) спектра в области максимума Si2p в составе образцов тканей печени $(a)$ и сердца $(b)$.

концентрацией более $90 \%$ и кислород с относительной концентрацией более 9\%. При этом в обоих типах тканей было установлено наличие атомов кремния в концентрации примерно 0.1 и $0.2 \%$ для образцов ткани печени и миокарда соответственно.

Анализ XPS-спектров образцов исследованных тканей (рис. 4) показал наличие максимума $\mathrm{Si}_{2 p}$ при значениях $102.5-103 \mathrm{eV}$, что характерно для окисленного кремния [28,33]. Это соответствует современным представлениям о метаболизме частиц por-Si в организме [34].

\section{3. Оценка ототропного эффекта гентамицина сульфата, вводимого с помощью дисперсных транспортных систем на основе изучаемых образцов частиц por-Si}

В группах с проведением акустического кондиционирования снижения амплитуды ОАЭ после АС и перед внутривенным введением изучаемых образцов не отмечено ( $p_{4 ; 5 ; 6,4}>0.05$ при сравнении с исходными данными). В экспериментальных группах за период наблюдения не отмечено летальных исходов, видимых отклонений в физическом состоянии и поведении животных как следствия острой токсичности применяемых доз изучаемых образцов дисперсных растворов. 
Уже после первого введения гентамицина отмечено значительное снижение амплитуды ОАЭ на частоте $6.4 \mathrm{kHz}$ в группе при совместном введении дисперсии из частиц por-Si $500-600 \mathrm{~nm}(p \leq 0.032$ по сравнению с остальными группами и $p<0.0001$ по сравнению с исходными данными) (рис. 5, $a$ ).

После третьего введения гентамицина в группе совместно с дисперсией из частиц por-Si 500-600 nm значимое снижение амплитуды ОАЭ наблюдалось на всех частотах (рис. $5, b)$.

При этом на частоте $6.4 \mathrm{kHz}$ отличия наблюдались и по сравнению с исходными данными $(p<0.0001)$, и по сравнению с показателями в группах оставшихся двух образцов $(p \leq 0.025)$. На частоте $5 \mathrm{kHz}$ при введении гентамицина совместно с por-Si 500-600 nm к этому времени отмечена депрессия амплитуды ОАЭ по сравнению с исходными данными $(p \leq 0.028)$ и не наблюдалось значимых изменений по сравнению с остальными группами. Амплитуда ОАЭ на $4 \mathrm{kHz}$ отличалась только от группы por-Si $250-300 \mathrm{~nm}(p=0.004)$ и в сравнении с исходными данными $(p \leq 0.006)$.

Product of distortion of the otoacousite emission The product of distortion (right ear)

The product of distortion (left ear)

The distortion product diagram (left ear $2 * F 1-F 2$ )
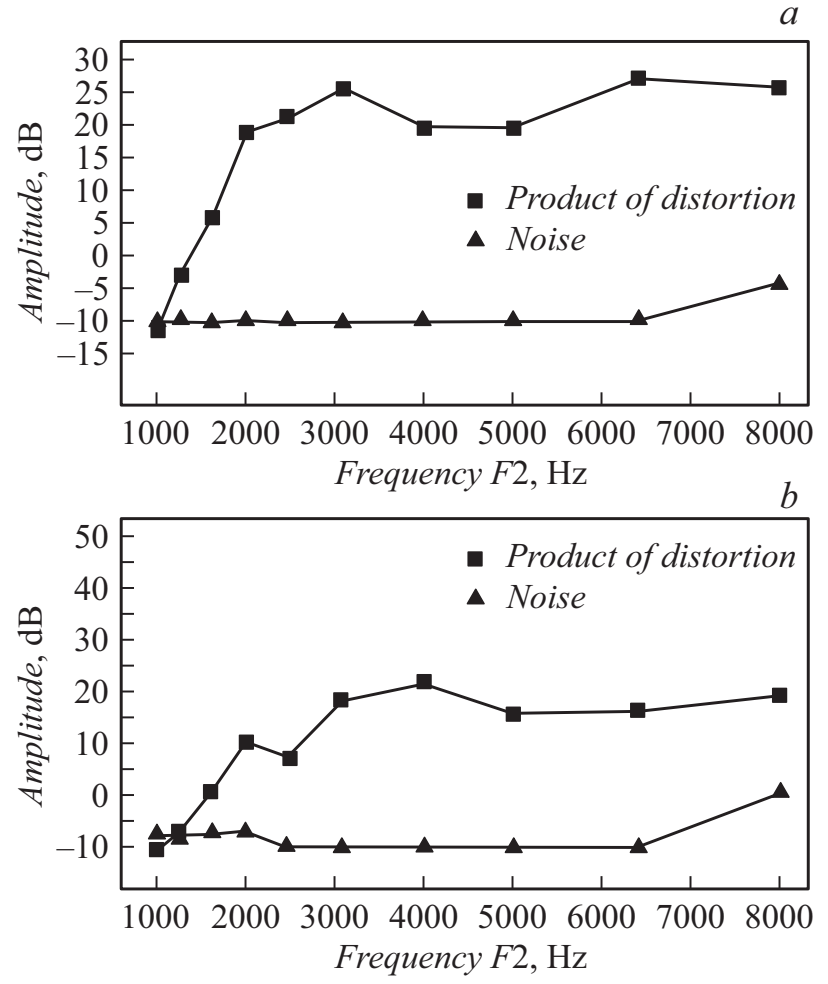

Рис. 5. Пример записи продукта искажения ОАЭ крысы на изучаемых частотах: $a-$ перед введением гентамицина и после проводимого акустического кондиционирования $(1000 \mathrm{~Hz}$, $105 \mathrm{~dB}, 2 \mathrm{~h}) ; b-$ после трехразового внутривенного введения гентамицина совместно с дисперсным раствором частиц por-Si $500-600 \mathrm{~nm}$.

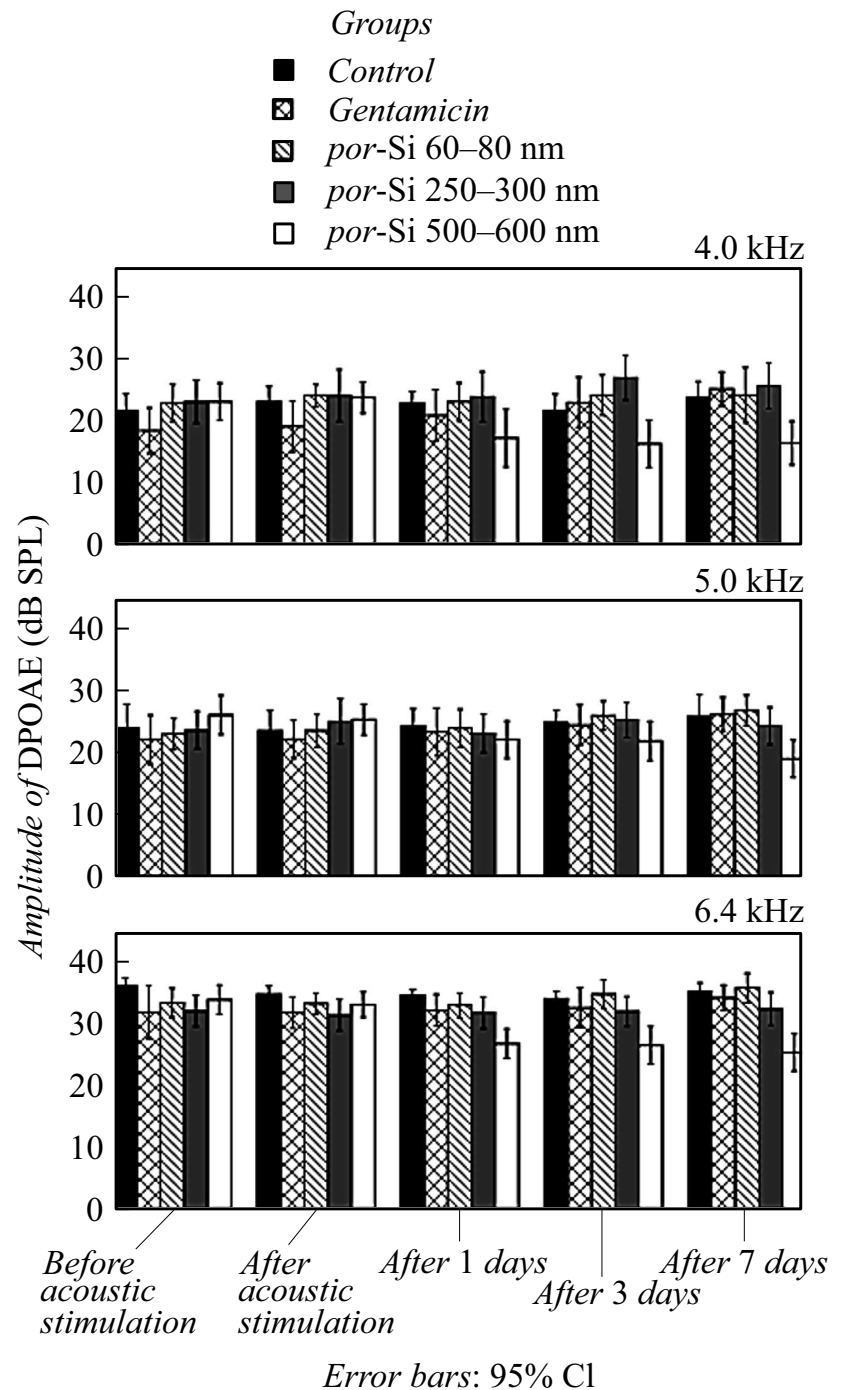

Рис. 6. Динамика изменения амплитуды ОАЭ ЧПИ (средние значения) на изучаемых частотах после внутривенного введения гентамицина совместно с частицами пористого кремния $60-80,250-300,500-600 \mathrm{~nm}$.

К 7 суткам наблюдения отодепрессивное действие в группе гентамицина, вводимого совместно с частицами por-Si 500-600 nm, нарастало на всех изучаемых частотах. Показатели амплитуды на каждой из частот отличались и при сравнении с исходными данными $\left(p_{4 ; 5 ; 6,4} \leq 0.006\right)$, и с другими группами $\left(p_{4 ; 5 ; 6,4} \leq 0.037\right)$ (рис. 6). При введении гентамицина совместно с частицами por-Si $60-80 \mathrm{~nm}$ и por-Si $250-300 \mathrm{~nm}$ такой динамики отмечено не было.

\section{Заключение}

Частицы por-Si мезо-макропористого типа в диапазоне размеров $60-80,250-300,500-600 \mathrm{~nm}$ получены методом электрохимического анодного растворения кремния с последующей обработкой ультразвуком. Оценка биологической совместимости дисперсий данных частиц 
в воде в отношении инфузорий Paramecium caudatum Keln показала токсичность объектов при высоких концентрациях ( $\approx 100 \mathrm{mg} / \mathrm{ml})$. При этом в концентрациях, характерных для доз, вводимых внутривенно, данные образцы не токсичны. Наибольшие показатели токсичности наблюдались у частиц среднего диапазона с размерами 250-300 nm, наименьшие - у образца 60-80 nm. Системное внутривенное введение дисперсного раствора частиц por-Si c размерами 60-80 nm обнаруживало нахождение электронно-плотных объектов схожего диапазона размеров и формы в ткани печени и миокарде. При этом подтверждалось присутствие кремния в исследуемых фрагментах органов: концентрация Si на поверхности сколов ткани печени и миокарда отмечалась на уровне 0.1 и $0.2 \%$ соответственно. По определению фазового состава было выявлено, что кремний в этих тканях присутствует в окисленном состоянии. Способность полученных образцов частиц por-Si выступать в качестве дисперсных транспортных систем для внутривенного введения лекарственных веществ оценивали по интенсивности ототропного эффекта официального медицинского препарата гентамицина сульфата, вводимого совместно с изучаемыми суспензиями. Наибольший ототропный эффект фармакологического маркера кохлеодоступности отмечен при использовании лекарственных контейнеров из частиц por-Si субмикронного размера $(500-600 \mathrm{~nm})$. Наблюдаемая отодепрессия при гибридном моделировании ототоксичности (использование минимальных доз и короткой экспозиции аминогликозидного антибиотика при предварительном акустическом кондиционировании слуховой системы) указывает на участие в биораспределении дисперсной транспортной системы фактора повышенной проницаемости гематолабиринтного барьера.

В настоящей работе использовалось оборудование научного парка СПбГУ „Физические методы исследования поверхности“ и „Культивирование микроорганизмов“. Образцы штаммов цианобактерий и инфузории предоставлены РЦ „Культивирование микроорганизмов“ Научного парка СПбГУ. Интерпретацию XPS-спектров проводили при поддержке гранта РФФИ № 18-03-00020-а. Работа в части РЭМ исследований выполнена в рамках Госзадания Минобрнауки РФ № 3.6288.2017/8.9 (БЧ). Биологический фрагмент на экспериментальных животных выполнен в рамках Госзадания МЗ РФ № 115091630046. Измерения методом спектроскопии кросс-корреляции фотонов проводились при поддержке гранта РФФИ № 17-32-50004 мол_нр.

\section{Список литературы}

[1] Исследование, технология и использование нанопористых носителей лекарств в медицине / Под ред. В.Я. Шевченко, О.И. Киселева, В.Н. Соколова. СПб.: Химиздат, 2015. $367 \mathrm{c}$.

[2] Fontana F., Shahbazi M.A., Liu D. et al. // Adv. Mater. 2017. Vol. 29. N 7. P. 1603239 . DOI: 10.1002/adma.201603239
[3] Galagudza M., Korolev D., Sonin D. et al. // J. Manufact. Techn. Manag. 2010. Vol. 21. N 8. P. 930-949.

[4] Liu Z., Li Yu., Li W. et al. // Adv. Mater. 2017. P. 1703393. DOI:10.1002/adma.201703393

[5] Handbook of porous silicon / Ed. by L. Canham. Cham, Switzerland: Springer, 2014. $1250 \mathrm{p}$.

[6] Ксенобонтова О.И., Васин А.В., Егоров В.В. и др. // ЖТФ. 2014. Т. 84. Вып. 1. С. 67-77.

[7] Спивак Ю.М., Беспалова К.А., Белорус А.О. и др. // Биотехносфера. 2017. № 3 (51). С. 69-75.

[8] Stojanovic V., Cunin F., Durand J.O. et al. // J. Mater. Chem. B. 2016. Vol. 4. N 44. P. 7050-7059. DOI: $10.1039 / \mathrm{C} 6 \mathrm{~TB} 01829 \mathrm{G}$

[9] Barnes T.J., Karyn L.J., Prestidge C.A. // Ther. Deliv. 2013. Vol. 4. N 7. P. 811-823. DOI: $10.1039 /$ C6TB01829G

[10] Spivak Yu.M., Belorus A.O., Somov P.A. et al. // J. Phys. Conf. Ser. 2015. Vol. 643. P. 010222. DOI: $0.1088 / 1742-6596 / 643 / 1 / 012022$

[11] Полковникова Ю.А., Леньшин А.С., Середин П.В., Минаков Д.А. // Неорганические материалы. 2017. Т. 53. № 5. C. $479-485$.

[12] Lenshin A.S., Kashkarov V.M., Spivak Y.M., Moshnikov V.A. // Mater. Chem. Phys. 2012. Vol. 135. N 2-3. P. 293-297.

[13] Леньшин А.С., Кашкаров В.М., Середин П.В. и др. // ФТП. 2011. Т. 45. Вып. 9. С. 1229-1234. [Lenshin A.S., Kashkarov V.M., Seredin P.V., Spivak Y.M., Moshnikov V.A. // Semiconductors. 2011. Vol. 45. N 9. P. 1183-1188.]

[14] Лисаченко М.Г., Константинов Е.А., Тимоченко В.Ю., Кашкаров П.К. // ФТП. 2002. Т. 36. Вып. 3. С. 344-348.

[15] Korotcenkov G., Cho B.K. // Crit. Rev. Sol. State. 2010. Vol. 35. N 3. P. $153-260$. DOI: $10.1080 / 10408436.2010 .495446$

[16] Tinsley-Bown A.M., Canham L.T., Hollings M. et al. // Phys. Stat. Solid. A. 2000. Vol. 182. N 1. P. 547-553.

[17] Spivak Yu.M., Mjakin S.V., Moshnikov V.A. et al. // J. Nanomater. 2016. Vol. 2016. P. 2629582. DOI: $10.1155 / 2016 / 2629582$

[18] Леньшин А.С., Кашкаров В.М., Середин П.В. и др. // ЖТФ. 2015. Т. 85. Вып. 7. С. $151-155$.

[19] Чубенко Е.Б., Редько С.В., Шерстнев А.И. и др. // ФТП. 2016. Т. 50. Вып. 3. С. 377- 381.

[20] Liu H., Hao J., Li K.S. // Acta Pharm. Sin. B. 2013. Vol. 3. N 2. P. $86-96$.

[21] ElKechai N., Agnely $F$., Mamelle $E$. et al. // Int. J. Pharm. 2015. Vol. 494. N 1. P. 83-101. DOI: $10.1016 /$ j.ijpharm.2015.08.015

[22] Liu Q., Li H., Xia Q. et al. // Int. J. Nanomed. 2015. Vol. 10. P. 7073-7088. DOI: $10.2147 /$ IJN.S94543

[23] Zou J., Pyykko I., Hyttinen J. // J. Otology. 2016. Vol. 11. P. $165-177$.

[24] Белорус А.О., Пермяков Н.В., Спивак Ю.М., Мошников B.A. Установка для получения пористых анодных оксидов металлов и полупроводников. Патент на полезную модель RU 167518 // Б.И. № 1. 2017.

[25] Pastukhov A.I., Belorus A.O., Bukina Ya.V. et al. // Proc. of the 2017 IEEE Conference of Russian Young Researchers in Electrical and Electronic Engineering (EIConRus). St. Petersburg, Moscow, 2017. P. 1183-1185. DOI: 10.1109/EIConRus.2017.7910770

[26] Belorus A.O., Bespalova K., Spivak Yu.M. // 2016 IEEE NW Russia Young Researchers in Electrical and Electronic Engineering Conference. St. Petersburg, 2016. P. 22-27. DOI: 10.1109/EIConRusNW.2016.7448108 
[27] Skoglund S., Lowe T.A., Hedberg J. et al. // Langmuir. 2013. Vol. 29. P. 8882-8891. dx.doi.org/10.1021/la4012873

[28] Комолов А.С., Лазнева Э.Ф., Герасимова Н.Б. и др. // ФТТ. 2016. Т. 58. Вып. 2. С. 367.

[29] Аверин И.А., Карманов А.А., Мошников В.А. и др. // ФТТ. 2015. Т. 57. Вып. 12. С. 2304.

[30] Komolov A.S., Zhukov Y.M., Lazneva E.F. et al. // Mater. Des. 2017. Vol. 113. P. 319.

[31] Терехова В.А., Воронина Л.П., Гершкович Д.В. и др. Биотест-системы для задач экологического контроля: Метод. реком. по практ. исп. стандартизованных тест-культур. М.: Доброе слово, 2014. 48 с.

[32] Паневин А.А., Журавский С.Г. // Бюллетень экспериментальной биологии и медицины. 2017. Т. 164. № 9. C. 347-350. ISSN: 0365-9615.

[33] Komolov A.S., Schaumburg K., Möller P.J., Monakhov V.V. // Appl. Surf. Sci. 1999. Vol. 142. P. 591.

[34] Anglin E.J., Cheng L., Freeman W., Sailor M.J. // Adv. Drug Deliver. Rev. 2008. Vol. 60. N 11. P. 1266-1277. doi:10.1016/j.addr.2008.03.017 